\title{
EXPLORING THE IMPACT OF PALLIATIVE CARE EDUCATION FOR CARE ASSISTANTS EMPLOYED IN RESIDENTIAL AGED CARE FACILITIES IN OTAGO, NEW ZEALAND
}

\author{
Lis Latta \& Jean Ross
}

\begin{abstract}
Palliative care is a growing specialty in New Zealand with many well-established hospices and an increasing number of hospital-based advisory services. Palliative care is an element of all healthcare services, and the aged care sector is one of those services where many of the residents have palliative care needs. In this setting, care assistants make up a large component of the workforce providing care for residents with increasingly complex needs.

This article reports the results of a study that used semi-structured interviews combined with a storytelling approach to explore the impact that attending a palliative care course had on care assistants' practice and their experiences of caring for dying residents. Factors influencing participants' ability to implement learning in the workplace were also identified.

The results showed that although attending the course had a positive impact on participants they were restricted in their ability to apply new learning in the workplace. Consequently recommendations are made to enhance workforce development in the aged care sector and to minimise barriers to the implementation of learning.
\end{abstract}

\section{INTRODUCTION}

In the last two decades, the palliative care specialty in New Zealand has undergone considerable growth with the Hospice New Zealand website reporting a $41 \%$ increase in hospice services since 1999. Despite this, the New Zealand Palliative Care Strategy (Ministry of Health 2001, p.43) identifies a common misconception among healthcare professionals that 'palliative care is only for those who are imminently dying' with a life expectancy of days or weeks. However, palliative care is increasingly recognised as appropriate for people suffering from a wide range of both malignant and non-malignant diseases over a 
much longer timeframe (Amella, 2003; Evans, 2002; Grbich, Maddocks, Parker, Brown, Willis \& Hofmeyer, 2005; Ministry of Health, 2001).

Many elderly people with life-limiting illnesses present with chronic complex diseases that have a more unpredictable trajectory than that of malignant diseases (Currow \& Hegarty, 2006.) These people often enter residential aged care facilities at a late stage in their illness because of a desire to remain at home for as long as possible. This means that when they do enter a residential facility they have more complex care needs from staff who require a broader range of skills (Currow \& Hegarty, 2006; Komaromy, Sidell \& Katz, 2000).

This situation has raised awareness of the palliative care needs of residents in aged care facilities, and resulted in increased demand for education, particularly from care assistants, who deliver the majority of direct patient care with little or no training (Smith, Kerse \& Parsons, 2005). Hospice New Zealand responded by developing the Palliative Care for Care Assistants course, which has been implemented by hospice services throughout New Zealand since September 2005. This programme aims to equip participants with the necessary skills to provide a high standard of end-of-life care within their role as care assistants. The programme acknowledges the crucial role that care assistants play in the provision of end-of-life care for the elderly and the significant impact they have on the quality of care that residents receive.

This article reports the results of a study exploring the impact that attending the course had on care assistants who were employed in residential aged care facilities throughout Otago. It determined whether new learning could be implemented in the workplace; what factors influenced this process; and whether care assistants believed it made any difference to the care they provided. Finally, recommendations are made to enhance workforce development in the aged care sector and to minimise barriers to the implementation of learning.

While the numbers involved in this study were small $(n=5)$, the findings were consistent with the lead author's experience of teaching care assistants as a palliative care nurse educator. Many of the issues that participants raised during the interviews were familiar topics for discussion during courses. There is also a significant lack of published research involving care assistants in New Zealand, which reflects a lack of acknowledgment and a subsequent lack of knowledge about care assistants and their role in the healthcare industry. This paper attempts to redress this problem by offering key insights into a largely unseen, yet vital group of healthcare workers who are charged with the care of some of the frailest members of our society. 


\section{BACKGROUND}

The primary goal of providing palliative care in any healthcare setting is to relieve suffering and enhance the remaining quality of life. While curative treatment may no longer be appropriate, there is much that can be done to improve quality of life through good symptom management and a holistic approach to care, in partnership with the patient, their family and the healthcare team.

In New Zealand, admission to a hospice programme is generally restricted to the last twelve months of life. However, palliative care can be initiated at any point along the illness trajectory and can be integrated into any healthcare setting (Evans, 2002) through the implementation of a palliative approach to care. This approach has been expressed as being particularly suitable to care of the elderly, many of whom suffer from illnesses that may ultimately lead to death (Evans, 2002; Froggatt, Poole \& Hoult, 2002; Hegarty, 2005; McDougall, Mathew, Broadhurst \& Chamberlain, 2001). Evidence suggests that many older people spend their last months or years in aged care facilities (Currow \& Hegarty, 2006; Grbich, Maddocks, Parker \& Brown et al., 2005), and the majority of people receiving palliative care fall into the older age bracket (Ministry of Health, 2002).

At the time this research was undertaken, $12 \%$ of the New Zealand population was over the age of 65 . However, it is estimated that by the year 2051 people over 65 years will comprise $25 \%$ of the population (Ministry of Health, 2002). This requires all healthcare professionals to have an understanding of the principles and practice of palliative care, and an ability to recognise when input from specialist providers is necessary to improve end-of-life care (Currow \& Hegarty, 2006).

In 2005 , it was estimated that there were approximately 28,000 people over the age of 65 years living in aged care facilities in New Zealand (Smith, Kerse $\&$ Parsons, 2005). Bearing in mind that New Zealand has a rapidly ageing population, it follows that there will be a corresponding increase in the number of people living and dying in residential aged care facilities. In order to predict future demand for health and disability services, research undertaken by the New Zealand Institute of Economic Research showed that the number of people living in aged care facilities is likely to increase by $83 \%$ by the year 2021, despite the age-in-place initiative that supports people to stay in their own homes for longer (New Zealand Institute of Economic Research, 2004). This situation calls for a significant investment in workforce planning and development to enable the healthcare workforce to cope with future demand. 
While many aged care facilities in New Zealand advertise that they provide palliative care, the New Zealand Palliative Care Strategy (2001, p.43) found 'scanty provision of palliative care in institutional settings for care of older people' and recommended the integration of a palliative approach supported by workforce development. This reflects current practice in the United Kingdom, North America and Australia (Amella, 2003; Arber, 2001; Ersek, 2003; Fitzpatrick \& Roberts, 2004; Frogatt, 2001; Hegarty, 2005). The Health of Older People Strategy (Ministry of Health, 2002) also identified a lack of coordination between long-term care and palliative care services and views palliative care education for staff in aged care facilities as the key to providing a seamless transition between specialist services and long term care.

INTERNATIONAL CONTEXT

A number of parallels exist in the provision of palliative care in residential aged care facilities in the United Kingdom, Australia and America. In the United Kingdom and Australia, aged care facilities are described as being situated at the interface between continuing and palliative care (Frogatt, 2001; Grbich et al., 2005). In America, aged care facilities are reported as a common location for end-of-life care (Hanson, Reynolds, Henderson \& Pickard, 2005). These parallels are congruent with the New Zealand context where it is common practice for older people to be transferred from specialist settings to aged care facilities for continuing care (Report of the Palliative Care Expert Working Group to the Cancer Control Steering Group, 2003), most of whom, it might be assumed, die there. Likewise, an unpublished study undertaken at the Otago Community Hospice in 2006 showed that $29 \%$ of the patients who were transferred from the hospice to an aged care facility died within two weeks of admission and 54\% died within six weeks (Thwaites, 2006).

While there are no data currently available to indicate the total number of deaths that occur in aged care facilities in New Zealand, literature shows that in the United Kingdom and America up to $23 \%$ of deaths occur in aged care facilities with at least $50 \%$ of permanent residents dying within the first year (Evans, 2002; Goodridge, Bond, Cameron \& McKean, 2005; Grbich et al., 2005; Katz, 2005). In Australia, Kristianson, Walton and Toye (2005) report that in $2002,86 \%$ of residents died in aged care facilities. In 2004 the Australian Government Department of Health and Aging responded by launching the Guidelines for a Palliative Approach in Residential Aged Care. The intention of this initiative was to improve the standard of end-of-life care provided in long term care settings. In 2005 Palliative Care Australia undertook a project to raise awareness of the Guidelines and promote their implementation by 
providing workshops for staff employed in aged care facilities. The Guidelines were subsequently evaluated by Palliative Care Australia in January 2007 and demonstrated the positive impact the programme had on participants (Palliative Care Australia, 2007).

THE ROLE OF CARE ASSISTANTS

Currently, there is a lack of published research in New Zealand involving care assistants. However three relatively recent reports provide valuable insight into the unique challenges they face. These reports show that, unlike their registered nurse colleagues, most care assistants have no formal work-related qualifications yet make up a significant proportion of the aged care workforce and provide the majority of direct patient care under the supervision of a licensee who may not necessarily be a registered health professional (Smith, Kerse \& Parsons, 2005; Ryan, cited in Walker, 2009). It is also important to note that care assistants are not regulated by any governing body or professional code of ethics and are not subject to the regulatory requirements imposed by health legislation (District Health Boards New Zealand, 2006; Smith et al., 2005).

Research conducted in 2006 by the Health Workforce Advisory Committee estimated there are approximately 25,000 care assistants employed in the aged care setting in New Zealand, most of whom are female, middle aged and in part time employment, including a large number of new migrant workers (Walker, 2009).

There are no minimum educational requirements for care assistants and only $17 \%$ have a formally recognised qualification, which is further reduced by a $29 \%$ staff turnover. Later figures show that staff turnover has risen to $40-50 \%$ per annum (Kedgley and Laban, 2010). This raises concerns about the quality of care residents receive, which is often dependent on staffing levels, the ratio of qualified to unqualified staff, the level of palliative care training and organisational attitudes (Report of the Palliative Care Expert Working Group to the Cancer Control Steering Group, 2003). While it is clear that care assistants provide the majority of care in these settings, they are largely dependent on their employer to provide training and supervision (Smith et al., 2005), but this is often not seen as a priority in a climate of considerable financial constraint.

There are similarities in care assistants' roles internationally with numerous studies describing care assistants as untrained and unregulated, yet forming a key component of the aged care workforce delivering the majority of care under the supervision of a registered nurse (Coffey, 2004; Ersek, 2003; Evans, 
2002; Fitzpatrick \& Roberts, 2004; Pelletier, 2005; Secrest, Iorio, \& Martz, 2005; Whittaker, Kernohan, Hasson, Howard \& McLaughlin, 2007). More specifically, Pelletier (2005, p.5) describes Certified Nurse Assistants, as they are known in America as:

Frontline staff who provide the majority of social interaction and physical care to nursing home residents. They are entrusted to implement many aspects of individualised care plans and manage extremely difficult situations involving conflict, ethical decisions, and the dying process.

Anecdotal evidence gathered from course participants during group discussions suggests that this is an accurate representation of the role that care assistants play in New Zealand aged care facilities. Despite the fact that few hold formal qualifications; the lead author's experience as an educator has shown that some care assistants have many years of experience, take great pride in their work and form strong, positive bonds with residents. However, without formal education, they are left to rely on their instincts, other staff, in-service training and institutional policies to guide them in the care they provide. Smith, Kerse \& Parsons (2005, p.2) identified similar concerns and explained that: "most care assistants learn to care for older people "on the job" and develop their skills and knowledge from experience and observation of other healthcare assistants. Without undermining the potential value of these measures Ersek (2000, p.16) believes that 'without the necessary education, no matter how well intentioned, delivery of high quality care for those who are dying is impossible. Kenny (2001, p.401) supports this argument by describing palliative care education as a necessity for all those involved in caring for people who are dying in any healthcare setting. She states: 'Good clinical practice is inextricably bound to education so one cannot be developed without the other'.

Member of Parliament, Hon. Ruth Dyson acknowledged the complexity of the situation in a speech to the 2004 Residential Care New Zealand Conference saying:

It is well-recognised that despite the best efforts of many service providers, care workers have for years been under-valued, underpaid and in many cases under-trained for work that is becoming increasingly demanding (cited in Bland, 2003, p.3).

This has resulted in a high staff turnover in many areas and a lack of information about care assistants' perspectives. Hon. Ruth Dyson identified a need to 
improve care assistants' access to work-related training and to ensure they are rewarded appropriately for the skills gained through education. Unfortunately these recommendations do not appear to have been acted on as the situation remains unchanged.

A more recent governmental report into aged care in New Zealand by Member of Parliament Sue Kedgley and former MP Winnie Laban in conjunction with Grey Power released in 2010, described the sector as:

Fast reaching crisis point, struggling to meet the growing needs of an ageing population and residents rising acuity levels... Alarmingly, as the level of dependency in aged care has increased, the number of trained nurses and staff available to look after residents has declined (p.5-6).

This evidence combined with the substantial projected increase in future demand for services, clearly indicates a burgeoning, under-trained, under-valued workforce struggling to cope under increasing demand from consumers and specialist palliative care services alike. The New Zealand Palliative Care Strategy (Ministry of Health, 2001) and the Health of Older People Strategy (Ministry of Health, 2002) have both called for workforce development in this important area. However, participating in educational activities is only the first step towards enhanced practice performance; the next step involves transferring what has been learned to the workplace.

\section{Palliative Care for Care Assistants Course}

The New Zealand Palliative Care Strategy (Ministry of Health, 2001) acknowledges a lack of training in palliative care for care assistants and home support workers and identifies a need to 'standardise education requirements for palliative care providers and the palliative care workforce' (Ministry of Health, 2001, p. 49). The Strategy also states that unless healthcare professionals receive sufficient training in palliative care it will be difficult to establish an enduring culture of palliative care or to implement a palliative approach in the clinical setting. These statements provided hospice educators throughout New Zealand with the impetus to pool their collective resources and experience in a united effort to develop a national, standardised course under the umbrella of the national organisation, Hospice New Zealand. The end result of this process was the development of an eight-hour palliative care course for care assistants that included: 
Principles of Palliative Care - philosophy, specialist and generalist care, holistic model of care, identifying residents with palliative care needs and examples of dying trajectories specific to the aged care setting;

Pain Assessment and Management - acute and chronic pain, pain thresholds and factors influencing pain perception, 'total' (holistic) pain model, assessment skills (including pain assessment in patients with dementia), principles of pain management including the analgesic ladder and a selfdirected learning guide about the cause and management of other common symptoms (e.g. breathlessness, constipation, dry mouth, pressure sores, confusion, poor appetite and weakness);

Communication and Support - understanding common fears and anxieties, emotional, social, cultural and spiritual needs and how to provide effective support for residents and their families;

Dying, Loss and Grief - the last 48 hours of life (managing common symptoms), understanding loss and grief, providing effective support, staff support and stress management.

A folder containing course materials, PowerPoint presentations, a student workbook and an electronic copy of all files on CD was provided for course facilitators. There was a minimal course fee to enable care assistants on a low income to attend, while still covering the costs of course delivery. While some employers provided financial assistance to enable staff to attend, other care assistants were required to pay the full cost themselves. At the end of the course, participants were required to complete a course evaluation and a certificate of attendance was issued. No written assessment was required.

While the feedback from course evaluations showed a consistently high satisfaction rate, course facilitators had no way of knowing if participating in the course had any impact on the learner or the care they provide. If the ultimate goal of education is to 'influence, improve or change practice so that it benefits patients and their families' (Kenny, 2003, p.192), it follows that educators have a responsibility to go beyond routine course evaluations by exploring the impact of education on participants and whether it influences or changes their practice on their return to the workplace. However there are a number of factors that influence this process and the degree to which new knowledge can effectively be transferred from the learning setting to the workplace. 
Doyle (2004) critiqued a number of studies relating to learning transfer, which originated in educational psychology and behaviourism, providing the foundational understanding of the cognitive processes involved. Learning transfer was originally perceived as being the result of a series of complex cognitive functions devoid from the influence of external or environmental factors. Since then, constructivist theory, which includes experiential and problembased learning with an emphasis on thinking and reflection, has added a great deal to what is known about learning transfer and the barriers and facilitators to implementing new knowledge in real situations (Doyle, 2004). The concept of learning transfer can be described as the 'so what?' [or the] 'now what?' phase of programme planning (Taylor, 2000, p.3).

From an employer's perspective, learning transfer is an important consideration in deciding whether to provide financial assistance and work-release to support staff to undertake further education. Therefore, it is reasonable for employers to expect to see a return on their investment in enhanced work performance (Taylor, 2000). For the learner, significant or transformative learning that relates to the practice environment can provide both personal and professional satisfaction through improved patient care and work performance. However, improved performance is not necessarily the result of participating in educational activities alone, but is influenced by numerous factors in the workplace (Hutchinson, cited in Kenny, 2001). The present paper identifies factors that both enable and prevent the transfer of learning to the work setting and are discussed in the results and discussion sections of this paper.

\section{METHOD}

Qualitative methodology was chosen as the most appropriate method for this research using descriptive, semi-structured interviews in combination with a storytelling approach. This provided an insight into the impact of education on participants and their practice, and their role as care assistants. Participants were interviewed individually with each interview lasting 60-90 minutes.

The aims of this study were threefold:

1. Explore how participants perceive their role as care assistants' and their experiences of caring for dying residents;

2. Identify the impact that attending the course had on participants and the 
care they provide-what difference did it make?

3. Discover whether participants were able to implement new learning on their return to the workplace, and identify factors that influence this process.

\section{THEORETICAL POSITIONING}

This study was situated in the educational positioning of Patton's evaluation theory, first posited in 1990 (cited in Patton, 2002). Broadly speaking, this includes any effort to judge or enhance human effectiveness through systematic data-based inquiry' (Patton, 2002, p.10). Patton argued that evaluation theory can be effectively achieved through a storytelling approach to 'illuminate the processes and outcomes of the programme' thus providing insight that can lead to a deeper understanding of the programme's impact on participants' day-to-day practice and ultimately patient care (Patton, 2002, p.10). Storytelling also illuminates participants' lived experiences and is an ideal way of giving voice to under-represented groups (McQueen \& Zimmerman, 2006). With this in mind, storytelling was chosen as the most appropriate tool for this study, thereby allowing us to share participants' experiences and perspectives by giving voice to their untold stories.

While preparing this research, a number of ethical issues were taken into consideration to ensure a rigorous process and the safety of all key stakeholders, which included course participants, Hospice New Zealand, and the Otago Community Hospice who delivered the course locally. All groups supported the research, which was subsequently reviewed and approved by the Otago Polytechnic and Otago Community Hospice Ethics Committees.

An important consideration was the changing role of the researcher from that of course facilitator. A statement in the invitation letter advised potential participants that the researcher was the same person who ran the course, which may have influenced their decision to participate. It was crucial that participants felt they could be honest during the interview to protect the credibility of data. Therefore interview questions were not directly linked to course content, structure or delivery, but rather participants' experiences of caring for dying residents, changes they had made as a result of attending the course, as well as enablers and barriers to the implementation of learning. The researcher had no line-management responsibilities to participants, no course work was submitted for assessment and all information disclosed remained confidential to each participant. 
Participants were recruited from the Otago Community Hospice education service database of previous course participants. Care assistants who completed the Palliative Care for Care Assistants course within the previous 3-12 months $(n=40)$ were eligible to participate. A letter was sent to all potential participants inviting them to be involved in the research along with an information sheet. Those who wished to participate replied by completing a tear-off section at the bottom of the letter which was returned to the research supervisor in an enclosed, freepost envelope. This process emphasised the researcher's changing role from educator to researcher. Otago Polytechnic letterhead was used for all correspondence, which further enhanced this process.

Eight positive responses were received, five of which fully participated. Three of the eight original participants withdrew due to family illness and workrelated stress. While this is a small group, the richness of data gathered from the interviews was more than enough to allow common themes to emerge, which were consistent with many of the issues that were raised by a variety of different course groups. Interviews were transcribed verbatim and analysed by highlighting significant statements from each interview. These statements were then colour coded and grouped according to each question. The data was then examined looking for recurrent words, patterns, themes and relationships and reported in the findings.

\section{RESULTS}

Five care assistants participated in this study. These participants came from the wider Otago region; four females and one male with ages ranging from 30-59 years. All participants identified as being from New Zealand European descent. The length of time participants had spent working in aged care ranged from 2-18 years. The only formal work-related educational qualification held was the National Certificate in Care of the Older Person, which two of the five participants had completed, while one had attended a short course run by the local Polytechnic 16 years ago. All participants completed the Palliative Care for Care Assistants course 3-4 months prior to participating in the research. Three worked in rest home level care facilities, one in hospital level care and one in a dementia care unit. Each participant was allocated a pseudonym and details regarding workplace, name and location were changed to protect anonymity.

How care assistants perceive their role and experiences of caring for dying residents:

Five themes emerged from this question, which are presented including ex- 
tracts from the participants' stories.

The first theme involved care for older people and commitment to their work. All participants expressed a genuine enjoyment and commitment to caring for the elderly, as the following excerpts show.

I like caring for [old] people. (Tricia)

I just love it; it's so nice to be able to be there for someone else. (Anne)

There was just something about elderly people that I was attracted to...I have always loved it; I don't like seeing elderly people struggle... I don't see myself doing anything else. (Donna)

I just like old people. I've always liked old people and they can tell you lots of stories about the past. (Robin)

I have never done anything like it but I would never leave my [job]. (Tracey)

This commitment was demonstrated through many examples where participants regularly went beyond their normal paid duties when a resident was dying.

On my days off I will go and sit with them [when they are dying] so they are not alone. (Donna)

If a family are coming from far away... you're allowed to be with that person until they actually come... even if you've got to come in on your days off to sit with them you can. (Robin)

The second theme is centred around privilege and reward. Participants expressed a real sense of privilege about being in a position that allowed them to care for people who were nearing the end of their lives. They also described caring for dying residents as one of the most rewarding aspects of their work.

I feel privileged to be with people when they are at the end of their life and sharing that experience with them...so I find it rewarding in lots of ways. (Tricia) 
It's such a privilege to be the one who is there at the last - a really profound moment. (Anne)

It is not sad. I think it is a real honour... it is so rewarding. (Tracey)

I always feel it is privilege to be sitting with someone who has passed. (Donna)

The third theme relates to the relationships participants developed with residents and their families, this was a central theme throughout participants' stories. It was evident that participants cared deeply about the residents in their care, which is reflected in the term 'extended family', that was often used to describe the relationships participants developed, particularly with those they had cared for over long periods of time or whose families were unable to visit often.

You know everything about them, you know their families, their past, their marriages....I always say we are like priests... they say things to you that you tell the kids later because they weren't there at that stage... and you are left with that. (Donna)

Robin made the following statement that was typical of many; "knowing residents over many years, you come to love them and their family and it's hard when they die.

The fourth theme focuses on the personal impact of working in an environment where many residents have complex needs and death is a frequent visitor. This was an issue that all participants identified as stressful, and likely to contribute to the high staff turnover. Caring for a resident through the dying phase, and their eventual death often resulted in a personal sense of loss for participants, which was compounded by the stressful nature of the work and the demanding workload as Tracey describes:

It's very hard, very heavy, difficult, stressful and emotionally draining, I don't know why people don't have counseling for some of the things that they see. You know people don't stop for five minutes; it's very difficult.

Anne also found this part of her work challenging saying: 'I don't think you can actually work in aged care and people not have an effect on you at some point even though you try very hard to keep yourself distant'. 
It's a tough job, emotionally tough. I'm a real sap, I get too involved... [crying]...I just get too emotionally attached to them and you try not to but you just... (Donna)

For the final theme, participants clearly identified themselves as being advocates who were willing to stand up to other staff if they believed a resident was not being treated well. Donna provided the following example of a staff member speaking about a 'difficult' resident: 'Ah, that silly old [resident], she has gone and done this or something like that. And I get really stroppy with them and say, "No, the reason she is doing that is because... and don't voice your opinion like that out loud"'. Anne also found herself challenging other staff on hearing inappropriate comments.

I just say, 'excuse-me, that's inappropriate'... I got a bit of a name for myself as being the bolshie one but I really don't care... if that was me lying in the bed or one of my family and I heard that conversation... that would not be acceptable.

Tracey also commented that:

The RNs that have come out from overseas think well that's the way it is and just put up with it and it is not. So until you actually did a course you don't know that. I would never have spoken up as forcefully as I have about the residents until I had known that I was correct to do so. (Tracey)

Care assistants are in an ideal position to be advocates given the close relationships they develop with residents. However, several participants stated that the challenge was making themselves heard by senior nursing staff who were not always receptive to their ideas and opinions.

Impact of education on participants and the care they provide - what difference did it make?

Validation of Instinctual Knowing:

The key theme that relates to the impact of the course on participants was validation of instinctual knowing. Instinctual knowing is a term that describes the sense of instinct participants either referred to or validated at some point during their interview. While some participants had made quite significant changes to their practice as a result of attending the course, they had previously 
relied on their instincts to guide them in their practice. For example, Robin stated: 'Instinct - you've either got it or you don't'. When asked how Donna knew what to do before attending the course she replied: 'For me, it was just instinct'. For many, attending the course had validated that what they were doing was right, which confirmed what they knew instinctually.

Several participants reported that the learning experience had empowered them to have confidence to teach other care assistants and to be stronger advocates for residents by being willing to challenge the way things are done. Anne provided the following example: 'I felt it empowered me to help other carers... I'm saying, "this isn't just made up"'.

I've always known... [what to do]... and doing your course has given me the confidence to do it. I have always known how to do it, it is just having the confidence and the right, believing you have got the right to do it and when somebody comes in and says you are not allowed to do it, you scream with them outside the door and then still go ahead knowing that you are doing the right thing. (Tracey)

For me, it was a confirmation of what I was already doing in a lot of senses. it was a confirmation of just being there, being present with them and really I think it just comes down to loving and just being available and listening and being still and being sensitive to the family. (Tricia)

\section{Impact of education on care provided}

The main changes participants had made to the care they provide as a result of participating in the course centered around pain management and having a better understanding of how to support residents and families when caring for dying residents. Robin gave the following example:

Learning how to cope when a resident dies, how to keep them comfortable, how to care for and support the family. Being respectful of families' needs and not being intrusive on their time with them... they don't have to die in pain and you make sure they are not alone.

An improved understanding of pain management and in particular how morphine works was helpful for many as illustrated by Tricia: 'I didn't realise that people don't have to die in pain...that made me feel a lot of relief'. Tricia had since made a deliberate effort to incorporate the skills she had gained at the 
course into her practice. In describing the impact the course had on her practice Tracey said: 'Until you do the course, you don't know those are challenges, you just blindly carry on thinking people are going to die that way'. Following the course, Tracey instigated a number of initiatives in her workplace including a staff register of those who were willing to sit with dying residents overnight so they would not be alone. This was an initiative that had also been established in other workplaces. Tracey also organised a 'Funeral Book' containing the death notices and service sheets of residents who had died, which was appreciated by staff and residents alike. Attending the course inspired Tracey to pursue further education by enrolling in the National Certificate in Support of the Older Person. Participants also encouraged their workmates to attend the course so they could all share the same level of understanding.

\section{Factors Influencing the Implementation of Learning}

In order to consolidate and retain what had been learned, participants needed opportunities to apply their learning in the workplace. However, if this process was impeded, the ability to transfer learning was minimized and the potential for improved work performance wasted. The final aim of this research identified both the enablers and barriers to the implementation of learning. Enablers are discussed first followed by the identified barriers.

Enablers included:

Management support: Providing extra staff when necessary, good institutional policies and procedures, in-service training, support for further education, valuing and respecting the knowledge gained, allowing for flexibility around routine cares and providing emotional support for staff when a resident dies. Those participants who had supportive managers were deeply appreciative of them and felt they were supported and encouraged to put their learning into practice.

Staff support: Re-organisation of workload among colleagues to meet increased care requirements of dying residents; staff notifying each other when a resident dies or is imminently dying to allow other staff the opportunity to 'say good-bye'.

Teamwork: mutual respect between all levels of staff who value and support each other and their respective roles and contribution to patient care. 
Barriers included:

Demanding workload: One barrier most participants shared in common was the demanding workload, which involved caring for many residents with complex needs. This often resulted in a task-focused approach to care. Tracey explained the tension between "what you want to do and what you can do makes it stressful'. Tracey also felt frustrated by the way some staff de-personalise residents because of the 'massive demands on [their] time.' The demanding workload is partly due to residents' high level of dependency and is further compounded by the organisation's financial constraints which limit staff numbers to skeletal levels.

Limited knowledge and understanding among other staff: A number of participants were frustrated by a lack of knowledge and understanding amongst other staff in their workplaces who had not undertaken the palliative care course. This involved a lack of understanding about how to care for dying residents appropriately including pain management, personal hygiene and comfort care. This was evident in the attitudes of some staff towards 'difficult' residents, which were deeply troubling for participants. These issues were compounded by the demanding workload and high staff turnover as illustrated by Tracey: 'I am one of the longest standing members on the afternoons'. (Tracey had been employed for 3 years). Staff attitudes were also a challenge for Anne:

I do get mad with one particular carer who as hard as you try, I don't think she is ever going to get it.... I find that she is my main challenge especially when someone is dying and she is inappropriate toward the family like she almost wants to become one of them, but we are there to support the family, they are not there to support us.

Tracey identified that new staff were in particular need of education to help them cope with their new role and to help reduce staff turnover. 'New staff can't deal with it because they don't know what they are doing...if they all did the course, I think you would keep staff longer'.

The degree to which poor understanding impacted on care appeared to depend on the facility manager. Those participants who spoke of having good management support encountered fewer barriers to implementing knowledge gained from the course. This is most likely due to their manager's influence on workplace culture, recruitment, orientation and ongoing investment in staff education. 
The results of this study show that care assistants, many of whom have no formal qualifications, largely rely on their instincts to guide them when caring for people who are dying. This is born from a desire to maintain human dignity and relieve suffering, which is at the very heart of palliative care philosophy. While the nature of the work is physically and emotionally demanding, it is inherently rewarding for those who choose to work in this area. However work-related stress and a lack of management support in some facilities is a likely contributing factor to the high staff turnover in this environment. Providing appropriate education for this vital part of the healthcare workforce is the key to meeting the palliative care needs of the elderly into the future, with the necessary skills and understanding to provide the required standard of care. However the environment participants return to is equally important in determining their ability to put learning into practice.

While this study demonstrated that attending the Palliative Care for Care Assistants course had a favorable impact on participants; they were restricted in the extent to which they were able to implement their learning. Therefore partnerships between specialist palliative care services and aged care facilities need to be developed to provide the necessary educational opportunities and ongoing support to help reduce the barriers to the implementation of learning in the workplace. As a result, the potential benefits of enhanced education to the organisation, its staff and the residents and families in their care will be maximised, with the ultimate goal being to empower care assistants to meet the needs of our frail elderly with skill and sensitivity into the future.

\section{RECOMMENDATIONS}

As this study has shown, the provision of palliative care in aged care facilities is both physically and emotionally demanding and requires sensitive and skilled care by people who are adequately trained to do so. The following recommendations identify the areas where significant development and policy change need to occur to prepare for the predicted increase in demand for residential aged care and to prevent distressing and avoidable experiences of substandard care.

While the results of this study cannot be generalised to the wider population, they provide a glimpse of life as a care assistant and the impact of education on the care they provide. Those who chose to participate in this study had a special interest in palliative care and were experienced carers who genuinely 
cared for older people, which drew them into this work and motivated them to attend the course. What is concerning is those care assistants who do not access palliative care education. There needs to be a significant effort made by policy-makers, aged care facility managers and hospice services to consider how best to meet the need for palliative care education for all care assistants. A cross-sectional analysis of the palliative care education needs, as well as the barriers and facilitators to providing effective end-of-life care in residential aged care facilities in New Zealand would be worthy of further research.

It is against this background that I make the following recommendations:

1. Lobby the Ministry of Health to:

a) Mandate formal education for care assistants employed in the residential aged care sector to commence within six months of employment;

b) Provide work-release, assistance with course fees and a graded pay structure on successful course completion to acknowledge and reward their increased skills and responsibilities and to provide an incentive to participate in ongoing education (Smith, Kerse \& Parsons 2005; Walker 2009);

c) Increase care assistants' basic wage to help improve staff retention and recognise care assistants' vital contribution to healthcare.

2. Introduce compulsory standards for practice and regulation of care assistants under the Health Practitioners Competence Assurance Act, 2003 (Walker 2009).

3. Minimise barriers to the implementation of learning in the workplace through:

a) Ongoing palliative care education for all levels of staff including facility managers, registered nurses, care assistants and general practitioners;

b) Establish formal partnerships between age care facilities and regional hospices for ongoing support, advice and palliative care education. Upskill experienced members of staff in aged care facilities to be resource people in their workplace. 
4. Establish the Liverpool Care Pathway for the Dying Patient (LCP) in aged care facilities supported by the local hospice. This pathway supplements the residents' care plan and provides standardised guidelines for all staff involved in the care of a dying resident. This would require additional targeted, regional funding for LCP facilitators to implement the pathway.

\section{REFERENCES}

Amella, E. 2003 Geriatrics and palliative care: Collaboration for quality of life until death, Journal of Hospice and Palliative Nursing, 5(1):40-48.

Arber, A. 2001 Student nurses' knowledge of palliative care: Evaluating an education module, International Journal of Palliative Nursing, 7(12):597-603.

Bland, M. 2003 All the Comforts of Home, Unpublished PhD thesis, University of Newcastle, Australia.

Coffey, A. 2004 Perceptions of training for care attendants employed in the care of older people', Journal of Nursing Management, 12:322-328.

Currow, D. and Hegarty, M. 2006 Residential aged-care facility palliative care guidelines: improving care, International Journal of Palliative Nursing, 12(5):231-233.

District Health Boards New Zealand. 2006 Future workforce: The non-regulated workforce in the health and disability sector, September, Acqumen Quality Solutions, Wellington, New Zealand. Retrieved September 5, 2007, from http://www.dhbnz.org.nz.

Doyle, S. 2004 The distance learner and the transfer of learning, The Open Polytechnic of New Zealand: Working Paper.

Dyson, Hon. R. 2004 Speech delivered to NZNO Residential Care NZ Annual Conference. Retrieved October 21, 2006, from http://www.beehive.govt.nz.

Ersek, M., Grant, M. and Miller Kraybill, B. 2005 Enhancing end-of-life care in nursing homes: Palliative Care Educational Resource Team (PERT) program, Journal of Palliative Medicine, 8(3):556-566.

Ersek, M., Miller Kraybill, B. and Hansberry, J. 2000 Assessing the educational needs and concerns of nursing home staff regarding end-of-life care, Journal 
of Gerontological Nursing, October:16-26.

Evans, B. 2002 Improving palliative care in the nursing home: From a dementia perspective, Journal of Hospice and Palliative Nursing, 4(2):91-99.

Fitzpatrick, J. and Roberts, J. 2004 Challenges for care homes: Education and training of healthcare assistants, British Journal of Nursing, 13(21):1258-1261.

Froggatt, K. 2001 Palliative care and nursing homes: Where next? Palliative Medicine, 15:42-48.

Froggatt, K., Poole, K. and Hoult, L. 2002 The provision of palliative care in nursing homes and residential care homes: a survey of clinical nurse specialist work, Palliative Medicine, 16:481-487.

Goodridge, D., Bond Jr, J.B., Cameron, C. and McKean, E. 2005 End-of-life care in a nursing home: A study of family, nurse and healthcare aide perspectives, International Journal of Palliative Nursing, 11(5):226-232.

Grbich, C., Maddocks, I., Parker, D., Brown, M., Willis, E. and Hofmeyer, A. 2005 Palliative care in aged care facilities for residents with a non-cancer disease: Results of a survey of aged care facilities in South Australia, Australasian Journal on Ageing, 24(2):108-113.

Hanson, L.C., Reynolds, K.S., Henderson, M. and Pickard, G.C. 2005 A quality improvement intervention to increase palliative care in nursing homes, Journal of Palliative Medicine, 8(3):576-584.

Health Workforce Advisory Committee. 2006 Care and support in the community setting: Discussion paper, June, Ministry of Health, Wellington, New Zealand. Retrieved March 5, 2007, from http://www.moh.govt.nz.

Hegarty, M. 2005 A review of the guidelines for a palliative approach in residential aged care: A palliative care and aged care collaboration, ACCNS Journal for Community Nurses, 10(3):7.

Katz, J.S. 2005 Palliative care in residential care facilities: A brief overview, International Journal of Palliative Nursing, 11(3):130-131.

Kedgley, S. and Laban, W. 2010 A report into aged care, What does the future hold for older New Zealanders? Retrieved February 21, 2010, from http://img. 
scoop.co.nz/media/pdfs/1010/Aged_Care_Report.pdf.

Kenny, L. 2003 An evaluation-based model for palliative care education: Making a difference to practice? International Journal of Palliative Nursing, 9(5):189194.

Kenny, L. 2001 Education in palliative care: Making a difference to practice? International Journal of Palliative Nursing, 7(8):401-407.

Kristianson, L., Walton, J. and Toye, C. 2005 End-of-life challenges in residential aged care facilities: A case for a palliative approach to care, International Journal of Palliative Nursing, 11(3):127-129.

Komaromy, C., Sidell, M. and Katz, J.T. 2000 The quality of terminal care in residential and nursing homes, International Journal of Palliative Nursing, 6(4):192-200.

Marie Curie Palliative Care institute Liverpool, Nov 2005 - version 11, Care of the Dying Pathway (lcp) (Care Home). Retrieved February 29, 2008, from http:// www.mcpcil.org.uk/liverpoolcarepathway.

McQueen, L. and Zimmerman, L. 2006 Using the interpretive narrative research method in interdisciplinary research projects, Journal of Nursing Education, 45(11): 475-478.

McDougall, G., Mathew, A., Broadhurst, V. and Chamberlain, S. 2001 An evaluation of an interprofessional palliative care education programme, International Journal of Palliative Nursing, 7(1):24-29.

Ministry of Health. 2001 The New Zealand Palliative Care Strategy, (ISBN 0-47824310-3), Wellington, New Zealand.

Ministry of Health. 2002 Health of older people strategy. Retrieved March 5, 2007, from http://www.moh.govt.nz.

Ministry of Health. 2002 Health of older people in New Zealand: A statistical reference. Retrieved October 11, 2007, from http://www.moh.govt.nz.

Ministry of Health. 2003 Palliative care: Report of the palliative care expert working group to the cancer control steering group. Retrieved April 12, 2007, from http://www.moh.govt.nz. 
Ministry of Health. 2006 National contract for age related residential care between district health boards and aged residential care providers. Retrieved October 11, 2007, from http://www.moh.govt.nz.

New Zealand Institute of Economic Research. 2004 Ageing New Zealand and health and disability services: Demand projections and workforce implications 2001-2021, A discussion document for the Ministry of Health by Mark Cox, Simon Hope \& Preston Davies. Retrieved October 21, 2007, from http:// www.nzier.org.nz.

Palliative Care Australia. 2007 Evaluation report: Introducing the guidelines for a palliative approach in residential aged care project. Retrieved October 28, 2007, from http://www.pallcare.org.au.

Patton, M.Q. 2002 Qualitative Research and Evaluation Methods (3rd ed.). California, USA: Sage Publications.

Pelletier, C. 2005 Feeding beliefs of certified nurse assistants in the nursing home, Journal of Gerontological Nursing, July:5-10.

Secrest, J., Iorio, D.H. and Martz, W. 2005 The meaning of work for nursing assistants who stay in long term care, International Journal of Older People in Nursing in association with the Journal of Clinical Nursing, 14(8b):90-97.

Smith, B., Kerse, N. and Parsons, M. 2005 Quality of residential care for older people: Does education for healthcare assistants make a difference? The New Zealand Medical Journal, 118(1214):1-11.

Taylor, M.C. 2000 Transfer of learning in workplace literacy programs, Adult Basic Education, Auburn, Spring, 10(1), Retrieved May 7, 2007, from http:// www.proquest.umi.com.

Thwaites, P. 2006 Transition: Hospice to Long-term Care, Masters Dissertation, Otago Polytechnic, Dunedin, New Zealand.

Walker, L. 2009 Caregivers Support Regulation and Education, Kai Tiaki Nursing New Zealand, December/January: 9. 